\title{
Performance comparison of fixed and single axis tracker photovoltaic system in large scale solar power plants in Malaysia
}

\author{
Baraa Mahmoud Dawoud, Siow Chun Lim \\ Faculty of Engineering (FOE), Multimedia University (MMU), Selangor, Malaysia
}

\begin{tabular}{|c|c|}
\hline Article Info & ABSTRACT \\
\hline Article history: & Malaysia is rapidly expanding the generation capacity of solar power through \\
\hline Received Jul 4, 2020 & large scale solar (LSS) projects with the aim to achieve $20 \%$ renewable energy \\
\hline Revised Aug 11,2020 & by 2025 . This has motivated many solar industry players to explore the \\
\hline & usage of solar PV with single axis tracker (SAT) system. However, many are \\
\hline Accepted Aug 21, 2020 & $\begin{array}{l}\text { still hesitant due to the lack of understanding on the comparative performance } \\
\text { between fixed mounted solar PV with solar PV with SAT system. This paper }\end{array}$ \\
\hline Keywords: & $\begin{array}{l}\text { aims to provide a comparative analysis on the performance of both systems. } \\
\text { Simulation using PVSyst } 6.83 \text { was performed in five potential LSS sites spread }\end{array}$ \\
\hline Capacity factor & across Peninsular Malaysia in Perlis, Kelantan, Pahang, Selangor and Johor \\
\hline Fixed system & $\begin{array}{l}\text { with the same installed capacity of } 10.32 \mathrm{MWp} \text {. The energy yield and capacity } \\
\text { factor for } 21 \text { vears were simulated. On the average, it was found that SAT }\end{array}$ \\
\hline Large scale solar & outperforms fixed mounted solar PV system by $15.08 \%$ based on their \\
\hline Photovoltaic & performance on their first year operation. \\
\hline
\end{tabular}

This is an open access article under the CC BY-SA license.

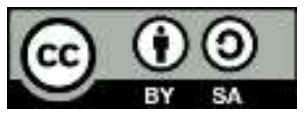

\section{Corresponding Author:}

Siow Chun Lim

Faculty of Engineering (Electrical), Multimedia University

Persiaran Multimedia, 63100 Cyberjaya, Selangor, Malaysia

Email: clsiow@mmu.edu.my

\section{INTRODUCTION}

The Malaysian government is committed to achieve $20 \%$ renewable energy capacity (RE) mix by the year 2025, with solar power being the biggest RE source. By the year 2025, it is targeted for 1.25GW of solar power to be injected to the grid, which makes up to $14 \%$ of the RE mix. To accelerate the achievement of this target, the large scale solar (LSS) scheme has been introduced in 2015 year. LSS is a competitive bidding programme to significantly lower the levelized cost of energy (LCOE) for the development of LSS photovoltaic (PV) plant [1], LSS is defined as solar photovoltaic plants each with a maximum export capacity (a.c. rating) of not less than $1 \mathrm{MW}$ but not more than 100MW which consists of solar PV modules, inverters, power conditioners, switchgear, switchboards, control boards, cables, mounting structures, earthing systems, lightning protection systems, buildings, lands and the associated ancillary systems such as electrical and mechanical installations, compound lighting, security surveillance systems. Unlike several predating schemes such as feed in tariff (FiT) and net energy metering (NEM), LSS was placed directly under the purview of the Energy Commission which strongly signifies the level of commitment of the Malaysian government towards its sustainable energy goal.

The identification of sites for the deployment of solar system is crucial. Various methodologies have been explored in several countries including Turkey [2, 3], Spain [4], Iran [5, 6], Indonesia [7], Saudi Arabia [8], Morocco [9], India [10], Serbia [11], and Afghanistan [12], In Malaysia, information on which systematic approach to be used for the selection of sites for solar farm is still severely lacking in the literature. 
Another equally crucial stage involved in the deployment of solar farms is the selection of PV system technology. In general, PV system can be either a fixed or a tracking system [13]. The single axis tracker (SAT) system can be further divided into two categories namely horizontal single-axis or vertical single-axis systems [14] and dual tracker system [15]. The attractiveness of these technologies have gradually increased due to the increasing affordability of solar energy technologies.

Fixed mounted solar PV is the most widely deployed solar PV system in the world largely due to its lower cost despite its lower energy yield as compared to SAT. SAT is a technique to track the sun from one side to another [16]. SAT system is not widely used in Malaysia although it gives more energy than the fixed structure [17]. SAT can be either east-west tracker which follows the sun east-west, but it is fixed in the site on the north-south direction, while north-south tracker follows the sun north-south but it is fixed in the site on the east-west direction [18]. Numerous studies comparing the performance of fixed and tracker system in terms of capacity factor and specific yield have been done in Egypt [19], Germany [20], Italy [21], South Africa [22], USA [23, 24], Thailand [25], India [26-29], China [30-31], Turkey [32], Saudi Arabia [33], Brazil [34], southern Europe [35] Germany [36], Nigeria [37], Jordan [38], Tunisia [39] and Estonia [40]. All of the aforementioned studies concluded that SAT performs 12\%-40\% better than fixed system. However, no study has been done on implementation of such systems at large scale i.e. more than $10 \mathrm{MW}$ which will be considered in this paper.

Since the launch of LSS, the response and acceptance amongst private industries has been overwhelming. Many of them has been motivated to explore on the application of SAT as compared to the conventional fixed mounted solar PV system with the belief that the former technology performs better than the latter technology. However, many of the solar industry players remains hesitant to invest and adopt SAT technology due to the vacuum in the information on the comparative performance of both technologies being deployed in Malaysia. It is therefore the prime motivation of this study which is to evaluate the performance of both of the aforementioned technologies in terms of energy yield and capacity factor. The evaluation will be performed using the widely adopted approach of simulation via PVsyst. The simulation outcomes shall serve as important guide for future deployment of SAT solar PV systems in Malaysia.

In this paper, the research methodology will be described first. Determination of the required simulation parameters will be explained. Then, the simulation results which include specific yield (SY), annual energy production (AEP) and capacity factor (CF) of fixed system with vs Single Axis Tracker will be presented and analysed.

\section{RESEARCH METHOD}

Figure 1 shows the overall flow of methodology employed for this study. Firstly, the identification process of LSS sites considered in this study will be explained. Then, the configuration of the system for simulation will be outlined. Next, system losses will be evaluated. Finally, the specific yield (SY) and average energy production (AEP) will be computed.

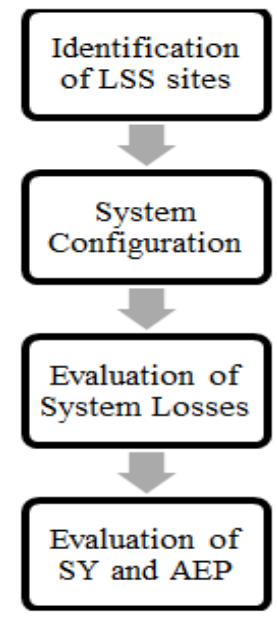

Figure 1. Project flow chart 


\subsection{Identification of LSS sites}

Five sites spread across Peninsular Malaysia have been identified for this study as summarized in Table 1. These states are selected as they are potential LSS sites. The states are also evenly distributed across Peninsular Malaysia with Perlis and Kelantan (Northern region), Selangor (Central region), Pahang (Eastern region) and Johor (Southern region).

The meteorological data of solar radiation, diffuse radiation, wind speed and ambient temperature are obtained from the PVsyst database Meteonorm 7.2. Meteonorm applies interpolation between weather stations, and a limited weighting on satellite imagery data to estimate irradiance parameters with a low density of available ground based data. Table 1 shows the solar radiation data for all five LSS sites. The global horizontal radiation (GlobHor) and the ambient temperature $\left(T_{-}\right.$Amb) are the same for both fixed and tracker. However, the difference is in the global incident in collector plane (GlobInc) which is caused by the tracker system as shown in Table 1. The tilt angle of the PV fixed mounted structure in all five sites is set to $8^{\circ}$ while the azimuth is set to zero which is facing south to get the maximum gain in solar irradiance from the sun. In short, this leads to optimum amount of energy produced from the system. On the other hand, the axis tilt and azimuth are both set to zero for single axis tracker (SAT) system. The minimum and maximum rotation angle $(\Phi)$ are $-45^{\circ}$ and $45^{\circ}$ respectively. All of these aforementioned factors affect the GlobHor for both fixed and SAT system. In terms of optical losses which is dependent on the incident angle modifier (IAM) phenomenon, the incidence loss (reflections due to the Fresnel's laws) is sufficiently well defined by a parameterization proposed by "Ashrae" (US standards office) [41]. It is also known as irradiance after reflection.

One of the major challenges in designing solar farm is to avoid shading loss while taking into consideration the land area constraint. The shading loss is due to the structure of array and the tilt of the solar panels. Another loss factor is the soiling loss. To get the optimum performance, the solar panels should be kept clean throughout its operational years to ensure that the solar irradiance is hitting the panel without being affected by dust the which can significantly reduce the efficiency. The effective global irradiance (GlobEff) will eventually be computed by taking into consideration all of the aforementioned irradiance loss factors.

Table 1. Potential LSS sites considered in this study

\begin{tabular}{|c|c|c|c|c|c|c|c|c|}
\hline \multirow[t]{2}{*}{ LSS Sites } & \multirow[t]{2}{*}{$\begin{array}{c}\text { Geographical } \\
\text { Location }\end{array}$} & \multirow[t]{2}{*}{ Altitude } & \multirow{2}{*}{$\begin{array}{l}\text { GlobHor } \\
\left(\mathrm{kWh} / \mathrm{m}^{2}\right)\end{array}$} & \multicolumn{2}{|c|}{$\begin{array}{c}\text { GlobInc } \\
\left(\mathrm{kWh} / \mathrm{m}^{2}\right)\end{array}$} & \multicolumn{2}{|c|}{$\begin{array}{c}\text { GlobEff } \\
\left(\mathrm{kWh} / \mathrm{m}^{2}\right)\end{array}$} & \multirow[t]{2}{*}{ Temperature } \\
\hline & & & & Fixed & Tracker & Fixed & Tracker & \\
\hline Perlis & $6.60^{\circ} \mathrm{N}, 100.19^{\circ} \mathrm{E}$ & $75.5 \mathrm{~m}$ & 1805 & 1812.7 & 2153.3 & 1742.4 & 2059.8 & 25.13 \\
\hline Kelantan & $5.84^{\circ} \mathrm{N}, 102.42^{\circ} \mathrm{E}$ & $27.6 \mathrm{~m}$ & 1717.5 & 1716.1 & 2015.7 & 1646.1 & 1919.2 & 27.16 \\
\hline Pahang & $1.66^{\circ} \mathrm{N}, 103.72^{\circ} \mathrm{E}$ & $17.8 \mathrm{~m}$ & 1664.6 & 1659.2 & 1944.8 & 1590.5 & 1850.7 & 26.79 \\
\hline Selangor & $2.71^{\circ} \mathrm{N}, 101.48^{\circ} \mathrm{E}$ & $18.5 \mathrm{~m}$ & 1612.2 & 1606.1 & 1859.6 & 1538.9 & 1764.9 & 27.6 \\
\hline Johor & $3.43^{\circ} \mathrm{N}, 102.75^{\circ} \mathrm{E}$ & $14.6 \mathrm{~m}$ & 1626.1 & 1623.5 & 1890.3 & 1599.2 & 1798.3 & 26.21 \\
\hline
\end{tabular}

\subsection{System configuration}

The LSS PV-Grid system considered in the scope of this study consists of solar PV modules, inverters, transformer, switchgear, cables, mounting structures, earthing system, and lightning protection system [42]. The system has 10.32MWp DC installed capacity with 10.31MWa.c. AC capacity. The simulation and analysis was carried out using PVsyst 6.83, PVsyst is a software for studying, simulation, and data analysis of PV systems. It is required from ST for all LSS bidder to perform this simulation by using similar tools to evaluate and declare the monthly and annual energy exported by each LSS plant [43].

The plant in all five sites consists of 800 strings with each string having 30 panels connected in series. Each of these string is connected in parallel with other string to eventually form an array. Each solar panel has a rated power of $430 \mathrm{Wp}$. There are mainly two types of inverters for solar plants namely central inverter and string inverter. Central inverter is commonly used for large solar system (LSS) due to its cost effectiveness while string inverter is commonly used for rooftop installation. The DC power produced from each solar string runs along cables to the combiner boxes where they are connected in parallel with other strings. From there, the DC power goes into the central inverter and converted to AC power. Central inverter units are physically much larger than string inverters. The plant consists of 3 units of central inverter with rated power $3437 \mathrm{kVA}$ at ambient temperature $45^{\circ} \mathrm{C}$. The central inverters are then connected to their respective transformer to step up from low voltage to medium voltage $(33 \mathrm{kV})$. Finally, the voltage is further stepped up to $132 \mathrm{kV}$ before being injected to the grid. Figure 2 illustrates the single line diagram of the system under study. Note that the same configuration is applied for both fixed and SAT plant in all five sites. To the best knowledge of the authors, the performance study at the LSS scale is yet to be done in Malaysia. Most, if not all, of the recent studies are focused on solar systems of much smaller capacity with rating from $20 \mathrm{Wp}-7.98 \mathrm{kWp}$ only [17-37]. Table 2 summarised the characteristics of the PV modules and central inverter used in this study. 
Table 2. Electrical properties of PV module and central inverter

\begin{tabular}{cccc}
\hline \multicolumn{2}{c}{ PV Module } & \multicolumn{2}{c}{ Central Inverter } \\
\hline Test Condition & STC & Maximum PV input voltage (V) & 1500 \\
Maximum power (Pmax) (W) & 430 & MPP voltage range for nominal power (V) & $875-1300$ \\
Open Circuit Voltage (Voc) (V) & 49.2 & Number of independent MPP & 1 \\
MPP Voltage (Vmpp) (V) & 40.6 & Maximum PV input current (A) & 4178 \\
Short Circuit Current (Isc) (A) & 11.19 & Nominal AC output power (KVA) & 3437 @ 45oC \\
MPP Current (Impp) (A) & 10.6 & Nominal grid frequency (Hz) & $50 / 45-55$ \\
Cell Properties & Monocrystalline & Efficiency & $99 \%$ \\
Standards & IEC61215, IEC61730 & Transformer rated power (KVA) & 3437 \\
& & Nominal grid frequency (Hz) & $50 / 45-55$ \\
& & LV / MV & $0.6 \mathrm{kV} / 10-35$ \\
& & Standards & IEC 61727, IEC 62116 \\
\hline
\end{tabular}

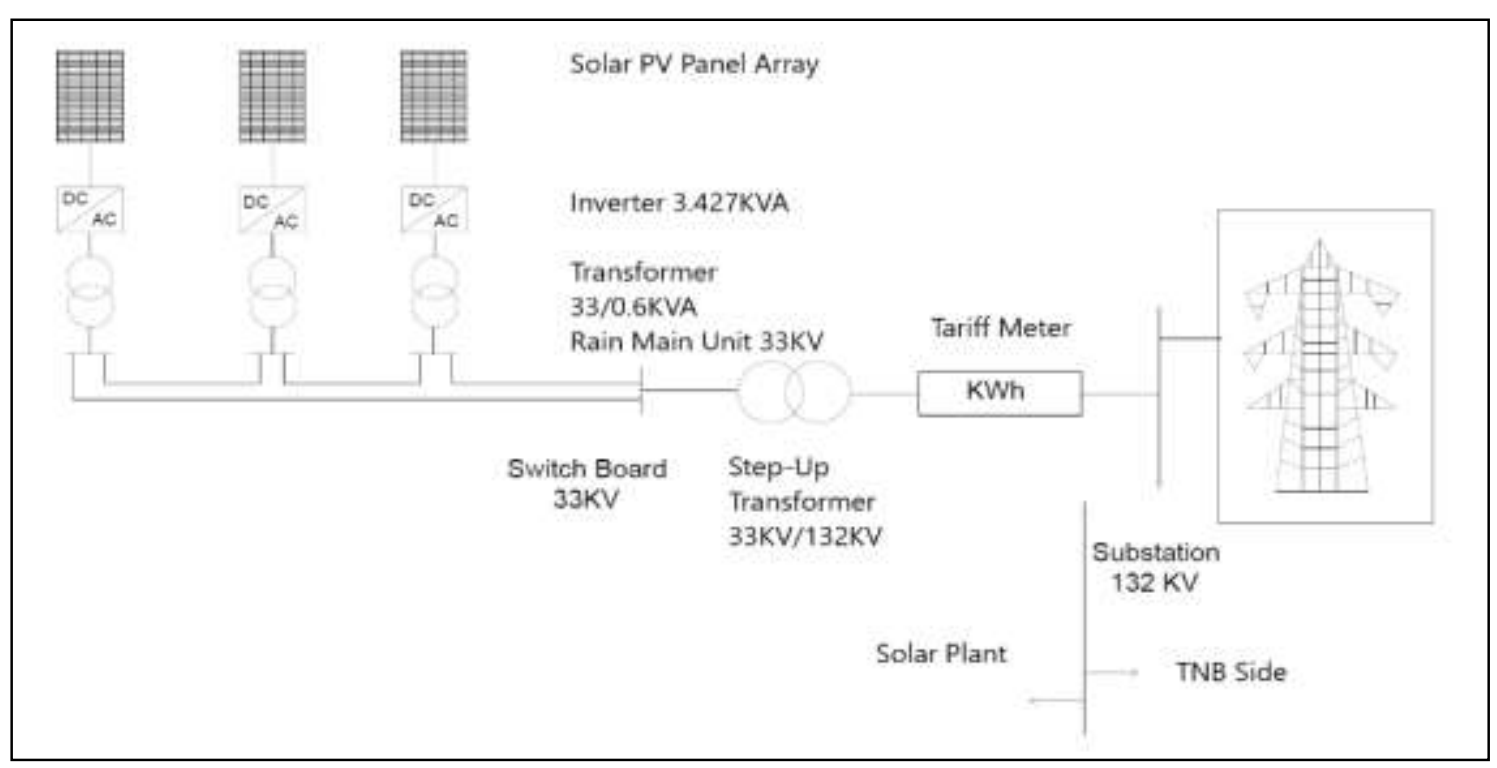

Figure 2. Schematic of the system

\subsection{Evaluation of system losses}

System loss consists of PV losses due to irradiance level and temperature level under standard test conditions (STC), PV module quality loss, light induced degradation (LID) loss and ohmic wire loss. Other contributor to system losses includes inverter efficiency which is directly affected by the ambient temperature at the site and the distance between the inverter and the transformer. In this study, central inverter in which both the inverter and the transformer are contained in the same box is used. Transformer loss is also considered.

\subsection{Evaluation of specific yield (SY) and average energy production (AEP)}

Once the evaluation of the system losses is completed, the specific yield (SY) and annual energy production (AEP) can then be computed. SY is defined as the annual net a.c. Export Energy of the PV System of the LSS Plant per kWp installed (kWh/kWp/year). Meanwhile, AEP is defined as the maximum a.c. rated capacity of the Large Scale Solar Plant supplying power to the Utility Power System measured at the Interconnection Point. The simulation will be performed for up to 21 years, which is the required period set by the local utility tenaga nasional berhad (TNB) and solar power purchase agreement (SPPA) in Malaysia.

\section{RESULTS AND DISCUSSION}

This present work aims to quantify the difference of a Specific Yield (SY), Annual Energy Production (AEP) and Capacity Factor (CF) of fixed system with vs Single Axis Tracker.

\subsection{Specific yield of fixed vs single axis tracker (SY)}

Table 3 shows the SY (kWh/kWp/year) of both fixed and SAT system at first year of operation. It can be clearly seen that the SY of SAT system is significantly higher than the SY of fixed system. This can be attributed to the role of the tracker in the SAT system which is able to maximize the amount of solar irradiation 
received by the panel. The highest difference in terms of percentage is in state Perlis which is $16.55 \%$ and this could be due to the high solar irradiance of $1805 \mathrm{kWh} / \mathrm{m} 2$ at this site as shown in Table 1 .

\subsection{Annual energy production of fixed vs single axis tracker (AEP)}

Table 3 also shows the AEP (MWh/year) of both fixed and SAT system. The AEP depends directly on SY and installed DC system size on the solar plant. Similar trend with the results in Table 3 can be observed with the highest percentage difference being in Perlis. On the average, there is a $15 \%$ improvement that SAT has over fixed systems. This falls in the range of 12\%-40\% improvement reported in the literature [19-40]. However, it has to be emphasized again that this is one of the first studies on the implementation of SAT in a large scale solar system manner.

Table 3. SY and AEP of fixed and tracker PV plant at first year operation

\begin{tabular}{ccccccc}
\hline State & SY & & Difference (\%) & \multicolumn{2}{c}{ AEP } & \multirow{2}{*}{ Difference (\%) } \\
& Fixed & SAT & & Fixed & SAT & \\
\hline Perlis & 1480 & 1725 & $16.55 \%$ & 1480 & 1725 & $16.55 \%$ \\
Kelantan & 1397 & 1620 & $15.96 \%$ & 1397 & 1620 & $15.96 \%$ \\
Johor & 1363 & 1566 & $14.89 \%$ & 1363 & 1566 & $14.89 \%$ \\
Selangor & 1311 & 1491 & $13.73 \%$ & 1311 & 1491 & $13.73 \%$ \\
Pahang & 1336 & 1525 & $14.15 \%$ & 1336 & 1525 & $14.15 \%$ \\
\hline
\end{tabular}

\subsection{Capacity factor (CF) of fixed vs single axis tracker (SAT)}

The Capacity factor of PV system expressed as percentage is normally defined as the ratio of AEP over the product of DC installed capacity and the total number of hours in a year ( 8760 hours). One of the requirements needed to be fulfilled is to achieve the capacity factor needed for every certain year [43]. The capacity factor is expected to decrease every year due to the degradation of the solar panel every year. As shown in Figure 2, Perlis exhibits the highest capacity factor due to its highest AEP value as shown in Table 3 previously. Figure 3 shows the comparison of CF over a period of 21 years as required in the SPPA [43] for both systems in Perlis. Similar trend is exhibited in Kelantan, Johor, Selangor and Pahang. It is worth mentioning that PV module manufacturer usually provides a warranty of up to 25 years and guarantees the performance starting from first year initial degradation to $98 \%$ and $0.55 \%$ after first year operation.

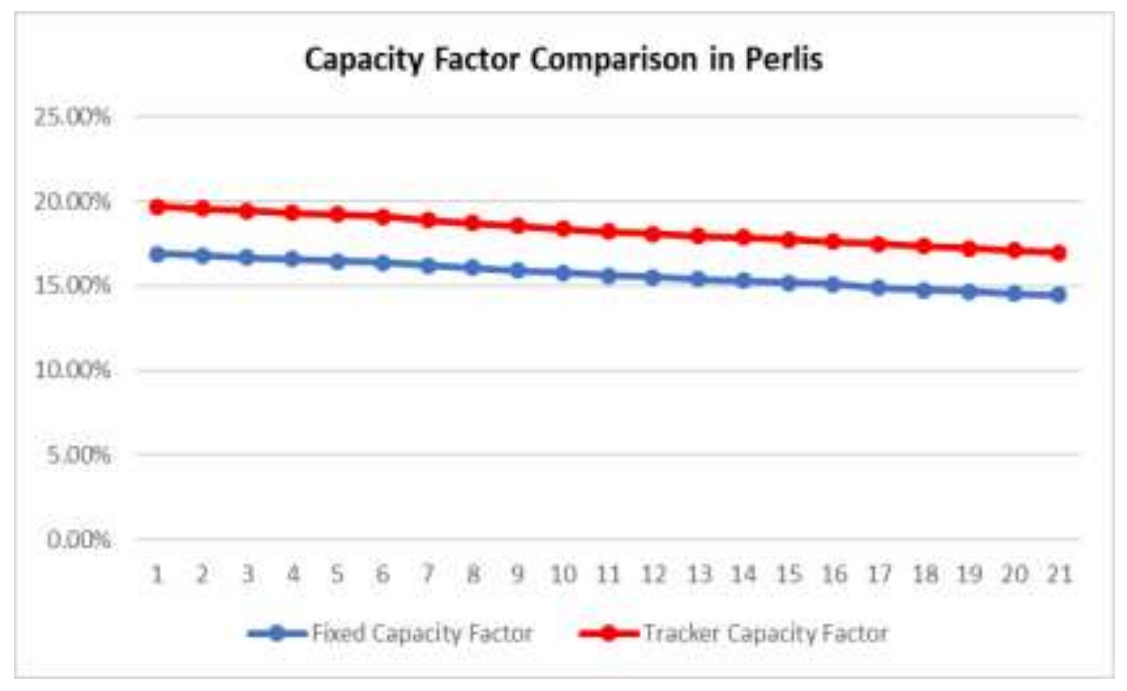

Figure 3. CF comparison between fixed and SAT in Perlis

Table 4 shows the CF of both fixed and SAT system at first year of operation for all five sites. It can be clearly seen that the CF of SAT system is significantly higher than the CF of fixed system. This is again due to the role of the SAT system as explained in previous section. 
With this as backdrop, the interest towards SAT system should be propelled as Malaysia will continue to encourage deployment of more solar plants due to lack of potential of other renewable energy resources such as wind in Malaysia [44].

Table 4. CF of fixed and tracker PV plant at first year operation

\begin{tabular}{cccc}
\hline State & CF for Fixed Technology & CF for Tracker Technology & Percentage difference \\
\hline Perlis & $16.89 \%$ & $19.70 \%$ & $2.81 \%$ \\
Kelantan & $15.95 \%$ & $18.50 \%$ & $2.55 \%$ \\
Johor & $15.56 \%$ & $17.88 \%$ & $2.32 \%$ \\
Selangor & $14.96 \%$ & $17.02 \%$ & $2.06 \%$ \\
Pahang & $15.25 \%$ & $17.41 \%$ & $2.16 \%$ \\
\hline
\end{tabular}

\section{CONCLUSION}

The strong push for the development of large scale solar PV system in Malaysia has prompted a surge in interest towards adopting and implementing the SAT system. This paper has concretely affirmed via simulation studies that the SAT system yields about $15 \%$ more energy than the conventional fixed mounted system when being implemented across Peninsular Malaysia at a large scale manner. The difference appears to be stable across Peninsular Malaysia due to a relatively strong degree of homogeneity in the meteorological condition of the five states. Similarly, the trend in the variation of capacity factor over a period of 21 years is also consistent throughout the five sites considered. However, future research on the cost effectiveness of SAT is warranted to complement the technical findings presented in this paper.

\section{ACKNOWLEDGEMENTS}

The authors would like to thank the Faculty of Engineering, Multimedia University for the facilities and resources provided.

\section{REFERENCES}

[1] National Energy Security 2012 Conference closing the energy supply-demand GAP, $28^{\text {th }}$ Feb 2012.

[2] M. Uyan, "GIS-based solar farms site selection using analytic hierarchy process (AHP) in Karapinar region, Konya/Turkey," Renewable and Sustainable Energy Reviews, vol. 28, pp. 11-17, Dec. 2013.

[3] N. Y. Aydin, E. Kentel, and H. Sebnem Duzgun, "GIS-based site selection methodology for hybrid renewable energy systems: A case study from western Turkey," Energy Conversion and Management, vol. 70, pp. 90-106, Jun. 2013.

[4] M. Sánchez-Lozano, C. Henggeler Antunes, M. S. García-Cascales, and L. C. Dias, "GIS-based photovoltaic solar farms site selection using ELECTRE-TRI: Evaluating the case for Torre Pacheco, Murcia, Southeast of Spain," Renewable Energy, vol. 66, pp. 478-494, Jun. 2014.

[5] M. A. Nazari, A. Aslani, and R. Ghasempour, "Analysis of Solar Farm Site Selection Based on TOPSIS Approach:," International Journal of Social Ecology and Sustainable Development, vol. 9, no. 1, pp. 12-25, Jan. 2018.

[6] M. Zoghi, A. Houshang Ehsani, M. Sadat, M. javad Amiri, and S. Karimi, "Optimization solar site selection by fuzzy logic model and weighted linear combination method in arid and semi-arid region: A case study Isfahan-IRAN," Renewable and Sustainable Energy Reviews, vol. 68, pp. 986-996, Feb. 2017.

[7] K. Aldrin Wiguna, R. Sarno, and N. F. Ariyani, "Optimization Solar Farm site selection using Multi-Criteria Decision Making Fuzzy AHP and PROMETHEE: case study in Bali," in 2016 International Conference on Information \& Communication Technology and Systems (ICTS), Surabaya, Indonesia, pp. 237-243, 2016.

[8] H. Z. Al Garni and A. Awasthi, "Solar PV power plant site selection using a GIS-AHP based approach with application in Saudi Arabia," Applied Energy, vol. 206, pp. 1225-1240, Nov. 2017.

[9] M. Tahri, M. Hakdaoui, and M. Maanan, "The evaluation of solar farm locations applying Geographic Information System and Multi-Criteria Decision-Making methods: Case study in southern Morocco," Renewable and Sustainable Energy Reviews, vol. 51, pp. 1354-1362, Nov. 2015.

[10] S. Sindhu, V. Nehra, and S. Luthra, "Investigation of feasibility study of solar farms deployment using hybrid AHPTOPSIS analysis: Case study of India," Renewable and Sustainable Energy Reviews, vol. 73, pp. 496-511, Jun. 2017.

[11] D. Doljak and G. Stanojević, "Evaluation of natural conditions for site selection of ground-mounted photovoltaic power plants in Serbia," Energy, vol. 127, pp. 291-300, May 2017.

[12] M. A. Anwarzai and K. Nagasaka, "Utility-scale implementable potential of wind and solar energies for Afghanistan using GIS multi-criteria decision analysis," Renewable and Sustainable Energy Reviews, vol. 71, pp. 150-160, May 2017.

[13] H. Mousazadeh, A. Keyhani, A. Javadi, H. Mobli, K. Abrinia and A. Sharifi, "A review of principle and sun-tracking methods for maximizing solar systems output" Renewable and Sustainable Energy Reviews, vol. 13, pp. 1800-1818, 2009. 
[14] M. Koussa, A. Cheknane, S. Hadji, M. Haddadi and S. Noureddine, "Measured and modelled improvement in solar energy yield from flat plate photovoltaic systems utilizing different tracking systems and under a range of environmental conditions," Applied Energy, vol. 88, no. 5, pp. 1756-1771, 2011.

[15] S. Heslop and I. MacGill, "Comparative analysis of the variability of fixed and tracking photovoltaic systems," Solar Energy, vol. 107, pp. 351-364, 2014.

[16] A. Z. Hafez, A. M. Yousef and N. M. Harag, Solar tracking systems: Technologies and trackers drive types-A review, Elsevier Ltd, vol. 91, pp. 754-782, 2018.

[17] M. Mahendran, H. L. Ong, G. C. Lee, K. Thanikaikumaran and E. My, “An Experimental comparison study between Single-Axis Tracking and Fixed Photovoltaic Solar Panel Efficiency and Power Output: Case Study in East Coast Malaysia", UMP Institutional Repository, 2013.

[18] R. C. Neville, "Solar Energy Collector Orientation And Tracking Mode", Solar Energy, vol. 20, no. 1, pp. 7-11, 1978.

[19] S. A. S. Eldin, M. S. Abd-Elhady, and H. A. Kandil, "Feasibility of solar tracking systems for PV panels in hot and cold regions," Renewable Energy, vol. 85, pp. 228-233, Jan. 2016.

[20] A. Şenpinar and M. Cebeci, "Evaluation of power output for fixed and two-axis tracking PVarrays," Applied Energy, vol. 92, pp. 677-685, Apr. 2012.

[21] G. C. Lazaroiu, M. Longo, M. Roscia, and M. Pagano, "Comparative analysis of fixed and sun tracking low power PV systems considering energy consumption,” Energy Conversion and Management, vol. 92, pp. 143-148, Mar. 2015.

[22] M. Mpholo, T. Nchaba, and M. Monese, "Yield and performance analysis of the first grid-connected solar farm at Moshoeshoe I International Airport, Lesotho,” Renewable Energy, vol. 81, pp. 845-852, Sep. 2015.

[23] H. Moradi, A. Abtahi, and R. Messenger, "Annual performance comparison between tracking and fixed photovoltaic arrays," in 2016 IEEE 43rd Photovoltaic Specialists Conference (PVSC), Portland, OR, USA, pp. 3179-3183, 2016.

[24] E. Drury, A. Lopez, P. Denholm and R. Margolis, "Relative performance of tracking versus fixed tilt photovoltaic systems in the USA", John Wiley and Sons Ltd, vol. 22, pp. 1302-1315, 2014.

[25] S. Chokmaviroj, R. Wattanapong, and Y. Suchart, "Performance of a $500 \mathrm{kWP}$ grid connected photovoltaic system at Mae Hong Son Province, Thailand," Renewable Energy, vol. 31, no. 1, pp. 19-28, Jan. 2006.

[26] K. Padmavathi and S. A. Daniel, "Performance analysis of a 3MWp grid connected solar photovoltaic power plant in India," Energy for Sustainable Development, vol. 17, no. 6, pp. 615-625, Dec. 2013.

[27] B. Shiva Kumar and K. Sudhakar, "Performance evaluation of 10 MW grid connected solar photovoltaic power plant in India," Energy Reports, vol. 1, pp. 184-192, 2015.

[28] K. N. Kumar, V. Subramaniam and K. KumarN, "Power Analysis of non-tracking PV system with low power RTC based sensor independent solar tracking (SIST) PV system" Materialstoday: Proceedings, vol. 5, no. 1, pp. 1076-1081, 2018.

[29] N. M. Kumar, M. R. Kumar, P. R. Rejoice and M. Mathew, "Performance analysis of $100 \mathrm{kWp}$ grid connected Sipoly photovoltaic system using PVsyst simulation tool," in Energy Procedia, vol. 117, pp. 180-189, 2017.

[30] Y. Yao, Y. Hu, S. Gao, G. Yang and J. Du, "A multipurpose dual-axis solar tracker with two tracking strategies," Renewable Energy, vol. 72, pp. 88-98, 2014.

[31] W. Nsengiyumva, S. G. Chen, L. Hu and X. Chen, Recent advancements and challenges in Solar Tracking Systems (STS): A review, vol. 81, Elsevier Ltd, 2018, pp. 250-279.

[32] C. Sungur, "Multi-axes sun-tracking system with PLC control for photovoltaic panels in Turkey", Renewable Energy, vol. 34, no. 4, pp. 1119-1125, 2009.

[33] H. Z. Al Garni, A. Awasthi and M. A. Ramli, "Optimal design and analysis of grid-connected photovoltaic under different tracking systems using HOMER,” Energy Conversion and Management, vol. 155, pp. 42-57, 2018.

[34] R. G. Vieira, F. K. Guerra, M. R. Vale and M. M. Araújo, "Comparative performance analysis between static solar panels and single-axis tracking system on a hot climate region near to the equator", Elsevier Ltd, vol. 64, pp. 672-681, 2016.

[35] T. Huld, T. Cebecauer, M. Šúri and E. D. Dunlop, "Analysis of one-axis tracking strategies for PV systems in Europe,” Progress in Photovoltaics: Research and Applications, vol. 18, no. 3, pp. 183-194, 2010.

[36] N. H. Helwa, A. B. Bahgat, A. M. El Shafee and E. T. El Shenawy, "Maximum collectable solar energy by different solar tracking systems," Energy Sources, vol. 22, no. 1, pp. 23-34, 2000.

[37] A. Bahrami, C. O. Okoye and U. Atikol, "Technical and economic assessment of fixed, single and dual-axis tracking PV panels in low latitude countries,” Renewable Energy, vol. 113, pp. 563-579, 2017.

[38] B. Hammad, A. Al-Sardeah, M. Al-Abed, S. Nijmeh and A. Al-Ghandoor, Performance and economic comparison of fixed and tracking photovoltaic systems in Jordan, Elsevier Ltd, vol. 80, pp. 827-839, 2017.

[39] R. Singh, S. Kumar, A. Gehlot and R. Pachauri, "An imperative role of sun trackers in photovoltaic technology: A review", Elsevier.Ltd, vol. 82, pp. 3263-3278, 2018.

[40] T. Tomson, "Discrete two-positional tracking of solar collectors," Renewable Energy, vol. 33, no. 3, pp. 400-405, 2008.

[41] A. Mermoud and B. Wittmer, "pvsyst user's manual pvsyst sa-route du," 2014.

[42] "Guidelines on large scale solar photovoltaic plant for connection to electricity networks [Electricity Supply Act (Amendment) 2015 (Act A1501)]".

[43] "Request for proposal large scale solar photovoltic plants with total capacity of 500MW for Peninsular Malaysia (LSS 3)",

[44] Lim, S.C., Meng, T.J., Palanichamy, C., and Eng, G.T, "Feasibility study of wind energy harvesting at TELCO tower in Malaysia”. International Journal of Energy Economics and Policy, vol. 9, no. 6, pp. 277-282, 2019. 


\section{BIOGRAPHIES OF AUTHORS}
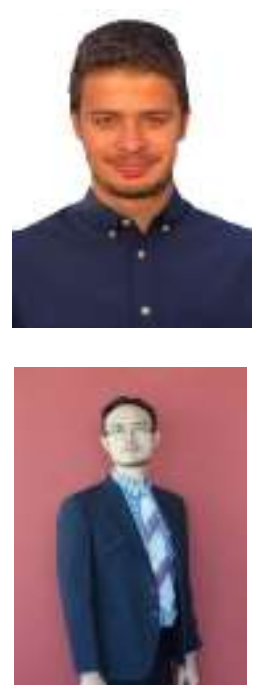

Baraa Dawoud received the Bachelor of Engineering (Hons), Electrical from Multimedia University, Malaysia. He is currently solar PV construction and commissioning lead - Nadec Solar Farm. His research interest includes solar energy.

Siow Chun Lim received his Ph. D. (Electrical Engineering) from Universiti Putra Malaysia. $\mathrm{He}$ is currently a Senior Lecturer, Programme Coordinator and Chair of Centre for Electric Energy and Automation (CEEA) at Faculty of Engineering, Multimedia University. He is also the Managing Director of LiRESAS Sdn. Bhd which provides consultancy on lightning risk assessment and electrical earthing systems. Siow is in the IEC TC 81 (Lightning Protection) committee working specifically in the development of lightning risk assessment standards. His research interest includes renewable energy, electrical earthing, lightning protection and engineering education. 